\title{
Application of Multimedia Platforms for Improving Child Education in Nigeria
}

\section{Agbaeze Ejem, Elvis Emmanuel Christopher, Juliet Nnenna Odii, Stanley Okechukwu Diala}

Department of Computer Science, School of Physical Sciences, Federal University of Technology, Owerri, Imo State, Nigeria

\section{Email address:}

ejem.agbaeze@futo.edu.ng (A. Ejem), elvredefined@gmail.com (E. E. Christopher), jnodii@yahoo.com (J. N. Odii), dialaokey1@gmail.com (S. O. Diala)

\section{To cite this article:}

Agbaeze Ejem, Elvis Emmanuel Christopher, Juliet Nnenna Odii, Stanley Okechukwu Diala. Application of Multimedia Platforms for Improving Child Education in Nigeria. Internet of Things and Cloud Computing. Vol. 5, No. 4, 2017, pp. 64-70.

doi: $10.11648 /$ j.iotcc. 20170504.11

Received: May 27, 2017; Accepted: June 13, 2017; Published: August 15, 2017

\begin{abstract}
This paper presents the application of multimedia platforms as an alternative to improving child education in Nigeria. The enormous challenges experienced in the present day child education as a result of children's natural vulnerability to distraction and loss of concentration in their educational pursuit have led to the research of this nature. An object oriented paradigm that initiates learning mode among children through the use of interactive animations that foster concentration has been proposed in this paper. A test run of the system demonstrated an efficient platform for improved child learning capacity with minimum distraction. The result of the research therefore is a domain independent-multimedia platform that addresses the prevalent Nigerian child education problem.
\end{abstract}

Keywords: Multimedia, Animations, Platforms, Interactive, Application

\section{Introduction}

Multimedia is characterized as the amalgamation of different computerized media kinds for example text, pictures, sound and video, with an incorporated multi-tactile intuitive application or presentation to pass on a message or information to a crowd of people. At the end of the day, multimedia signifies an individual or a little gathering of people utilizing a personal computer to interface with information that is illustrated in different types of media, by choosing more than once what to see and hear next". [1]. Multimedia is the combination of various types of media. This incorporates text, graphics, sound, video, etc. For example, a presentation including sound and video clasps would be viewed as an interactive multimedia demonstration. Educational programming that includes animation, sound, and text is called multimedia programming. CDs and DVDs are regularly thought to be multimedia structure since they can store a great deal of information and most types of multimedia require a lot of storage space [2]. As indicated by [3], multimedia platform gives a learning situation that is self-managed, learner-controlled and individualized. This implies the kid can learn at his/her own pace and figures out what he/she need to learn per time. Multimedia innovation is a standout amongst the most energizing advancements in this data age. The quick development of interactive media innovation in recent times has achieved the basic changes to computer processing capabilities, entertainment and different educational training formats. Instructive multimedia applications are from multiple points of view like printed course books and other educating and reference materials in that they arrive in a wide range and assortment. Some interactive media applications are expansive and far reaching while others are more engaged. [4] hypothesizes that apart from customary books, personal computers give another methods for showing narrating and writing to kids. Personal Computers can be the means for introducing these stories to kids on CD-ROM or to assess youngsters or stories they have perused. Also with access to the web, personal computers can be a methods for adapting more about their general surroundings subsequently encouraging the general learning process. Instruction is a piece of regular day to day existence. To procure it one needs to learn. Learning is a demonstration or procedure of picking up information or aptitude by examining, honing or being instructed or experiencing something. The demonstration of learning in a classroom or 
studying without anyone else's input most circumstances to youngsters appeared to exhaust and all the more so a gigantic assignment. Games which is a framework in which players take part in a simulated clash characterized by guidelines that result in a quantifiable outcome before the period of personal computers was quite for amusement and unwinding for kids. From research made, youngsters take in more while playing recreations or utilizing recordings and movements. The study is concerned with the design of personal computer aided media framework for youngsters incorporating video animations. The utilization of interactive media in ventures for learning has been successful as it has expanded broadly efficiency and consistency standards among the tutees and their instructors. According to the research carried out by [5], individuals recollect $20 \%$ of what they see, $40 \%$ of what they see and listen, however around $75 \%$ of what they see and hear and do simultationeously.

The role of interactive multimedia and its viability have been the subject of many reviews. This paper plans to showcase the significance of multimedia in early child education in Nigeria. It is needful to say that the utilization of multimedia innovation has extraordinary impact in schools, colleges and research foundations in the Western nations. In these nations, the innovation is being viewed as a key player to advancement in all repercussions and fundamental part of education. As indicated by [6] and [7] as referred to in [8], information correspondence is conceivable through different channels and if data is displayed through more than one channels, it will enhance learning particularly among youngsters.

The essential part of multimedia is learning by doing. The tutees see the items and after that learn. Multimedia have one of a kind capacities to encourage schooling on account of the parallels amongst multimedia and common way youngsters learn, that is through visual data and symbolism. Vocabulary learning guideline and educational modules ought to reexamine their utilization of multimedia inside their presentation [9].

There has been a substantial attempts to introduce multimedia learning platforms in our secondary and tertiary education as indicated by many works that has been done in this respect, but little attention has been paid to its application in our nursery and primary education where the foundation of learning is very paramount. This paper is geared towards the introduction of multimedia learning in child education so as to improve their learning capacities by presenting learning in form of games and videos.

\section{Review of Related Literature}

According to a study conducted by [10], the power of multimedia lies in the fact that it is multi-sensory, stimulating the many senses of the audience. It is also interactive, enabling the end users of the application to control the content and flow of information. This has introduced important changes in the educational system and impact the way information is communicated to the learners. In the same vein, [11] expressed that multimedia technology adds new dimension to learning experiences because concepts were easier to present and comprehend when the words are complemented with images and animations. Stating further that it has been established that learners retain more when a variety of senses are engaged in impacting knowledge; and the intensity of the experience aids retention and recall by engaging social, emotional and intellectual senses. The evolution of multimedia has made it very possible for learners to become more involved in their work. With multimedia technologies, they can create multimedia applications as part of their project requirements. This would make them active participant in their own learning process, instead of just being passive learners of the educational content. Moreover, [12] in his study, identified many types of multimedia communication platforms, some of which include computer hardware's, computer software's, public address systems, slides, overhead projectors, opaque projectors, videos, cassettes, audiotapes, cassette recorders, flip, time sequence, stream charts, Diorama still motion pictures etc. furthermore, a study by [13] agree to the notion that multimedia resources facilitate access to all human knowledge, anytime, and anywhere in a friendly, multimodal, efficient and effective way, by overcoming barriers of distance, language and culture, and by using multiple Internet-connect devices.

\subsection{Child Education in Nigeria}

Childhood education is a branch of education that is concern with the teaching of young children whether formally or informally up until the age of about five. In every advanced society it is truthful that educational training is the best way to national development and there is a need to carry the children along since this stage is the bedrock whereupon all other educational levels builds. Once a youngster or child misses that early stage it is typically troublesome for the learner to get a fresh start [14]. In line with this notion, the National Policy on Education [15] stipulates that it should be included in mainstream education. Formal education begins from pre-primary education as provided in day-care centers and nursery schools to children aged 3 through 5 years. It is enriched by the informal traditional upbringing given to children from 0 through 3 years which makes them ready for school. Although the government is not directly involved in the establishment of day-care centers and nursery schools.

The operational objectives of child education as stated in the National Policy of Education [15] include:

(1) Effecting a smooth transmission from the home to the school;

(2) Preparing the child for the primary level of education;

(3) Providing adequate care and supervision for the children while their parents are at work;

(4) Inculcating in the child the spirit of enquiry and creativity through the exploration of nature and environment, art, music and playing with toys, etc;

(5) Develop a sense of co-operation and team spirit;

(6) Inculcating social norms; 
(7) Learn good habits, especially good health habits; and

(8) Teaching rudiments of numbers, letters, colours, shapes, forms etc. through play.

The achievement of the stated objectives of early childhood education and care in Nigeria is brought about via the following means:

a) establishing pre-primary sections in existing public schools and encouraging both community and private efforts in the provision of early childhood education;

b) making provision in teacher education programmes for specialization in early childhood education;

c) ensuring that the medium of instruction will principally be the mother tongue or the language of the immediate community.

d) ensuring that the main method of teaching in the childhood education centers will be through play, and that the curriculum of teacher education is appropriately oriented to achieve this;

e) regulating and controlling the operation of early childhood education - to this end, the teacher pupil ratio is set at $1: 25$;

f) setting and monitoring a minimum standard for early childcare centers in the country;

g) Ensuring full participation of government, communities and teachers' associations in the running and maintenance of early childhood education facilities.

The contents of the policy are detailed and planned because it is the stated goal of the Nigerian government that its education system concerning its young children should be comparable to all others in the world. Yet to an extent some of these policies have not been implemented and as such child education dwindles and is left at the mercy of the privately-owned child educational institutions.

\subsection{Different Approaches to Child Education in Nigeria}

According to [16], the following are different approaches to effective child education in Nigeria:

(1) Role-playing Approach: This refers to activities where a child or group of children simulate a scenario by assuming specific roles. In the classroom, children can work through a situation and practice behavior for the real world. When children do role plays, it stimulates their imagination and enhances their social development, encourages friendship through cooperation, listening and turn taking". Therefore, role play is very important for child education.

(2) Dramatization Approach: This is a great way to solidify learning. It can also mean turning a novel into a movie or a play. This is an effective learning tool because it involves the children intellectually, physically, socially, and emotionally. It can challenge children's perceptions about their world and about themselves.

(3) Construction Approach: In construction approach, children under guidance and direction of the teacher demonstrate the ability to imagine, and create objects, events situation or models showing various issues that represent their world views, experience and perception. To achieve the purpose of construction in the classroom both print and non-print materials can be conveniently used. For instance, paper, wood, clay and other locally produced materials can be effectively used by children in construction activities.

(4) Activity Approach: This is an approach adopted by a teacher to emphasize his or her method of teaching through activity in which the children participate rigorously and bring about efficient learning experiences. It is a child-centered approach.

(5) Story-Telling Approach: This allows children to digest information more easily because it connects that information to emotions. It is important because it is effective at teaching in a way that children can easily remember.

\subsection{Problems of Child Education}

[17] in their paper identified the following as the problems of child education: professional qualification of caregivers/teachers, resources, staff-child ratio and funding etc.

(1) Professional Qualification of Caregiver/Teachers: it is generally known that qualified teachers are needed for the training of young children in our institutions of learning. However, most of the institutions that teaches or trains young children in Nigeria are privately owned. Therefore they tend to employ unqualified teachers in order to cut cost and this affects the young children educational pursuit in the negative as they will not be tutored professionally.

(2) Resources: According to [18], the quantity and quality of resources available for any educational programme would determine schools systems capacity for the implementation of the type of educational programme. Despite the importance of resources, most schools systems own by the Nigerian government lack resources to implement most of the educational program suitable for the young children.

(3) Staff-Child Ratio: National Policy of Education [15] stated that in order to have an effective learning, teacher to pupil ratio is $1: 25$. But most time a visit to some of the institutions in Nigeria shows that the class rooms are crowded with children. This makes the teacher to give less attention to the children. In this case the children are prone to distraction and loss of concentration as they are many in one class.

(4) Funding: In child education, adequate funds need to be made available for provision of many resources and activities which include stimulating materials for teaching, training and re-training of staff (teachers and caregivers), enrichment and sensitization of programmes through regular workshops, monitoring, feeding, immunisation, supervision and inspection, report writing, publications, school meals and training manuals among others. The sad thing however is that Nigerian child education is ridiculously underfunded. 
This could be linked to the low budgetary allocation to the education sector in the nation.

\subsection{The Multimedia Technology Approach}

Multimedia technology refers to interactive, computerbased applications that allow people to communicate ideas and information with digital and print elements. It applies interactive computer elements, such as graphics, text, video, sound, and animation. Multimedia technology approach is a new innovation that is aimed at improving the teaching and learning process. It combines five basic types of media into the learning environment: text, video, sound, graphics and animation, thus providing a powerful new tool for education especially in young children. The development of multimedia technologies for learning offers new ways in which learning can take place in schools and the home.

\subsection{Essence of the Multimedia Approach}

(1) Improved Learning: The Multimedia Approach is expected to show a massive rate of increase in learning in the children. This is because it initiates fun through the multimedia platform. This approach should be able to make the children happier while learning and attain heights of excellence when tested on what has been taught.

(2) Interactivity: Interactivity is a mutual action between the learner, the learning system and the instructor. Learners learn faster and have better attitude towards learning while using interactive multimedia system especially in children.

(3) Flexibility: The Multimedia Approach is flexible. It should be used efficiently at the learning center, home use and practice. It can also be used in networks, intranets and also downloaded on the internet. This distributed learning approach allows more flexibility.

(4) Practical-Oriented: The Multimedia Approach should be capable of representing real life situations that children familiarize themselves with. Video simulations, learn-by-viewing and other multimedia processes that help actualize this.

(5) Consistent Learning: All children learn the same principles and skills. Multimedia systems typically allows teachers and instructors to better organize and structure learning materials and this alone can result in learning advantages.

\section{Research Findings}

Nigerian government have tried for several decades to improved her citizen's educational pursuit through the National Policy on Education which have been amended several times to suit her young children's educational pursuit. The objectives of Federal Government of Nigeria on education have been achieved largely to an extent yet more work is needed. We discovered from this research that the traditional class room learning is boring for the young children mostly because this class rooms sometimes are overcrowded which makes the children not to be interested with what the teacher is teaching rather they tend to be looking up and down looking for who to pinch thereby losing concentration. Also we discovered that most of our institutions are not properly supervised by the government which leads them to engage in unhealthy practices such as learning in a dirty, unconducive environment, employing unqualified teachers that endanger the educational pursuit of our youngsters. From the foregoing, it is obvious that there is a need for a paradigm shift to child education in Nigeria and that paradigm shift is multimedia application in child learning. Multimedia approach of learning has the capacity to arouse the children's curiosity and provide them with clear impressions-they watch it as games or videos without knowing that learning is going on. Multimedia allows learning in different styles- some children learn by interpreting text, while others may require graphical or mathematical representations. Multimedia approach allows a learning environment that is self-paced, learner-controlled. This means that the child can learn at his/her own pace and determines what he/she want to learn per time. Although the implementation and maintenance of multimedia platforms is expensive, yet its benefits to the education of youngsters cannot be over emphasized.

\section{Improving Child Education in Nigeria Using Multimedia Platforms}

The multimedia technology approach is a major improvement to child education as it overcomes in its entirety the hitches of the present way of delivering child education in Nigeria. The approach is a full software that concentrates on the three basic domains of the child's syllabus all in one pack. These domains are English Language, Mathematics and General Basic Science. With modern technology, it presents these domains in a simple, easy-to-understand, user-friendly interface suitable to pump up the enthusiasm for learning in young children. Multimedia content is also represented, creating a game like experience even as learning is going on. It overcomes the problem of tutor availability as it is resident on the computer system and can be accessed at any given time by the child.

\section{Results and Discussion}

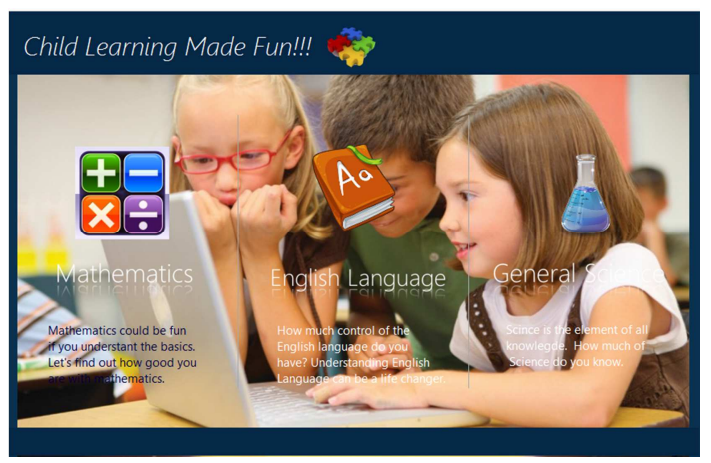

Figure 1. Homepage Interface. 
From figure 1 the children can open up any of the study modules depending on which subject they want to learn per time. At the end of the learning exercise, there are questions to answer in relation to what they have learnt. This learning and doing helps to improve their rates of learning thereby enhancing early academic development.

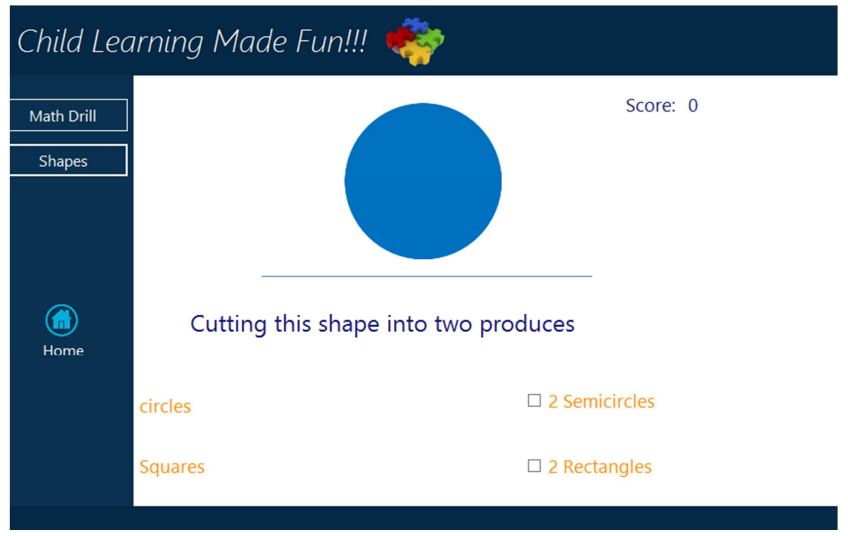

Figure 2. Mathematics Interface.

Figure 2 shows up as you click on mathematics in figure 1. When you take your mouse over the left pane, a navigation pane shows up with mathematics drill and shapes options. If you want to do shapes identification, you click on shapes and as you correctly identify the shape, the score is added for you.

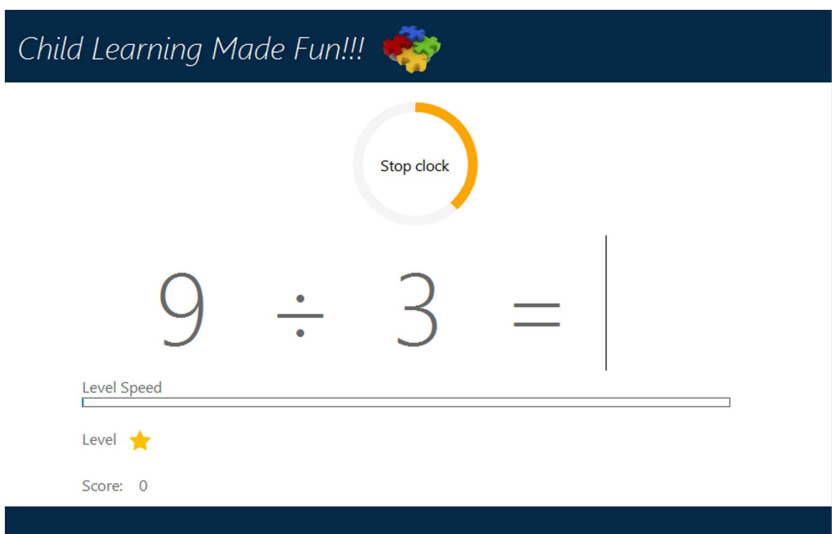

Figure 3. Mathematics Interface Extension.

This interface shows up when you click on mathematics drill. When the child is unable to attempt the questions, the stop clock terminates that session and give him or her an opportunity to try again. The blinking cursor is where the child will type the answer.

Figure 4 shows up as you click on English Language in figure 1 . When you take your mouse over the left pane, a navigation pane shows up with Parts of Speech and Spell the word options. If you want to do identification of the parts of the speech of the word shown, you click on Parts of speech option and as you correctly identify the parts of speech, the score is added for you.

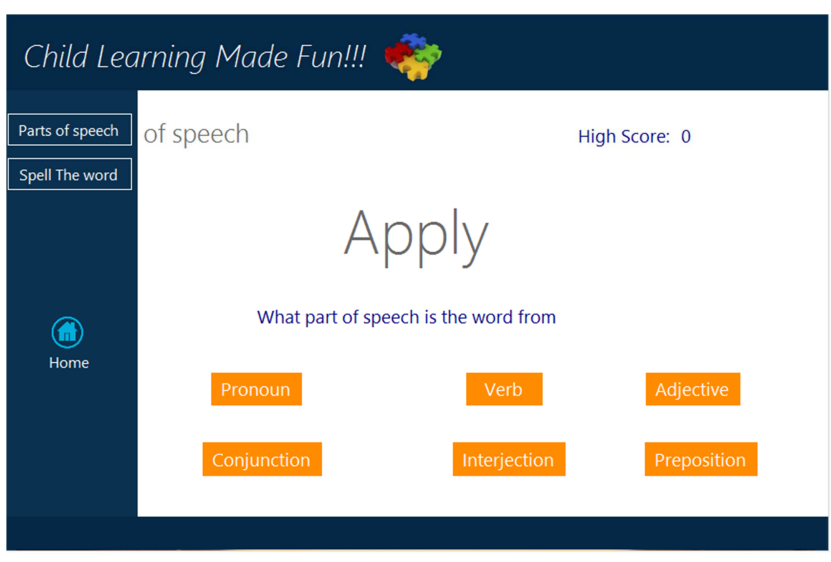

Figure 4. English Language Interface.

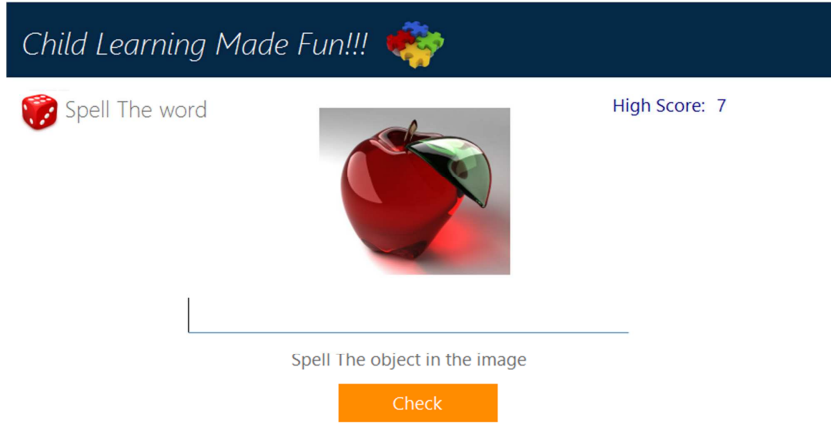

Figure 5. English Language Interface Extension

This interface shows up when you click on Spell the word option. As spell the word correctly, the score is added to you but when you do not get the spelling correctly it will tell you "Wrong spelling" play again.

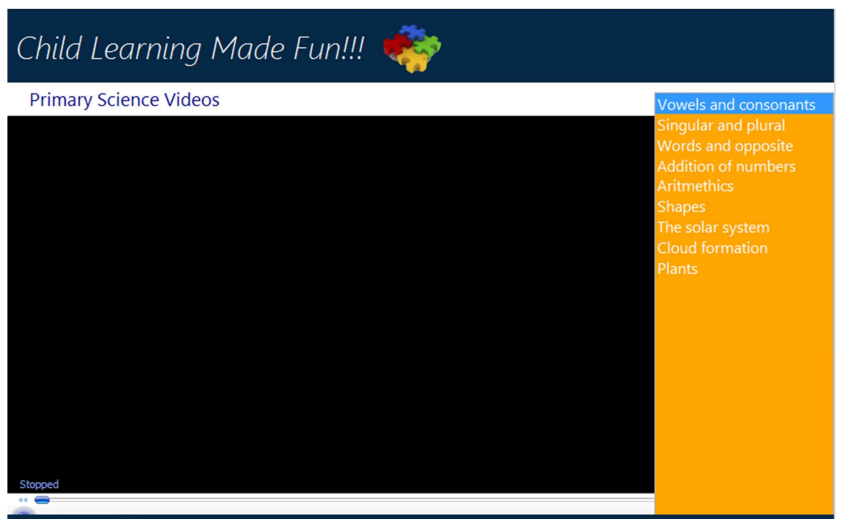

Figure 6. General Science Interface.

When you click on General science in figure 1, the interface shows as shown in figure 6 , when you move the mouse to the right pane, a yellow background navigation pane shows up also containing all the videos in this module. Assuming you click on arithmetic, the video in figure 7 shows up, teaching the child basics of subtraction. 


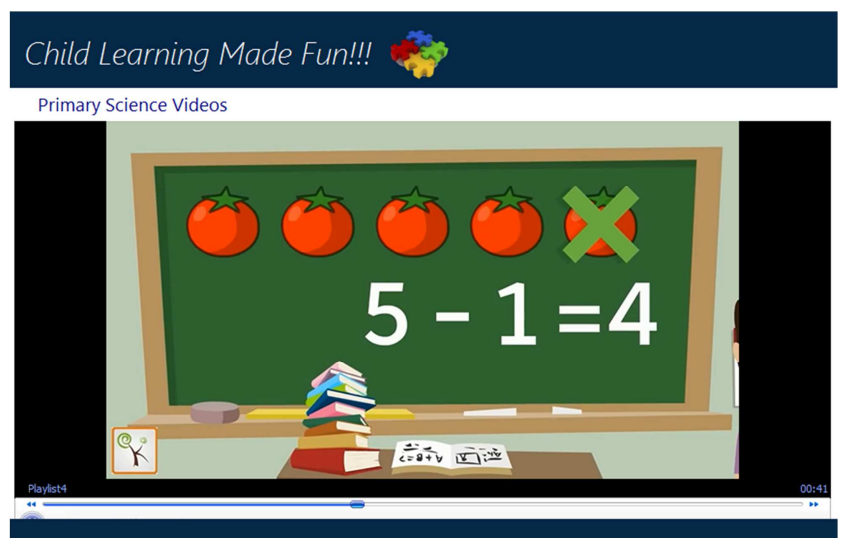

Figure 7. Arithmetic Video-Subtraction.

\subsection{Areas of Application of the Research}

Areas in which this work can be applied include:

(1). Child Daycare centers and Playgroup facility.

(2). Home study and practice sessions.

\subsection{Areas for Further Research}

1. The multimedia system should be expanded to contain junior grade and senior grade curriculum.

2. The system can also be implemented on a mobile app platform using Android technology because of its portability, robustness and fast accessibility.

\subsection{Conclusion}

The previous system of child education in Nigeria continues to encounter enormous challenges due to children natural vulnerability to distraction and loss of concentration. We have been able to develop an object oriented paradigm that initiates an alternative learning mode among children through the use of interactive animations which promotes adequate concentration among children thereby mitigating their lack of concentration and distraction.

Multimedia technology platforms is undoubtedly the concept that will bring the desired solution to child education in Nigeria since it arouses the mind of the young children as they tend to watch it as games and videos for fun without knowing that learning is going on. The application of multimedia technology platforms to child education is already successful in other countries of the world. Nigerian government role should be to incorporate it in their national policy on education for better child education. The implementation of this platform is expensive yet it benefits to the development of Nigerian children cannot be overemphasized.

\subsection{Recommendation}

We recommend this software to all Nursery and Basic Grade schools all over the world as it would enhance child learning efficiency if adopted and properly utilized.

\section{References}

[1] Agnew, P. W., Kellerman, A. S. \& Meyer, J. (1996). Multimedia in the Classroom. Boston: Allyn and Bacon.

[2] Emmanda C. C (2014), "Role of Multimedia in Early Childhood Education" | Teacher II | Carbon Elementary School| Limay, Bataan, Philippines.

[3] Oshinaike, A. B. and Adekunmisi, S. R., "Use of Multimedia for Teaching in Nigerian University System: A Case Study of University of Ibadan".

[4] (2012). Library Philosophy and Practice (e journal). Paper 682. http://digitalcommons.unl.edu/libphilprac/682

[5] Adam, T., \& Filtro, A. (1997). Using ICT to improve the education of students with learning disabilities. Learning to Live in the Knowledge Society, (pp. 63-70) University of Moscow on 27th February 2016.

[6] Lindstrom, R. (1994). The Business Week guide to multimedia presentations: create dynamic presentations that inspire. New York: McGraw- Hill.

[7] De Bagui, M.-C., Mac Cartney, B., \& Manning, C. D. (1998). Generating typed Animations. Retrieved:

$\mathrm{http}: / /$ nlp.stanford.edu/ $\sim \mathrm{wcmac} /$ papers/td- 1 rec 06.pdf on $5^{\text {th }}$ April 2016.

[8] Daniels, M. (1995). Designing a strategic Information System Planning Methodology for Malaysian Institution of Higher Education. On $10^{\text {th }}$ September 2016.

[9] Junaidu. (2008). Multi-ontology based multimedia annotation for domain-specific information retrieval. Proceedings of the Sensor Networks, Ubiquitous, and Trustworthy Computing. On $23^{\text {rd }}$ January 2016.

[10] Kim D., \& Gilman A. D (2008), Effects of text, audio, graphic aids in multimedia instruction for vocabulary learning, IFETS, II, 114-126.

[11] Neo, M. and Neo, T. K. (2000). Multimedia learning: using multimedia as a platform for instruction and learning in higher education Paper presented at the Multimedia University International Symposium on Information and Communication Technologies 2000 (M 2 USIC'2000), October 5-6, 2000, Petaling Jaya, Malaysia.

[12] Ogunbote, K. O. and Adesoye, A. E. (2006). Quality assurance in Nigerian academic libraries networked multimedia services. Journal of Library and Information Science, Vol. 3. No. 1 \& 2 pp. 100-111.

[13] Babajide, J. F. T. and Bolaji, O. A. (2003). Perception of lecturers and pre-service teachers towards the use of communication media in teaching pure and applied sciences in related disciplines. Proceedings of Conference, Lagos: pp. $23-40$.

[14] Ubogu, F. N. (2006). Trends in digital library services in academic libraries in South Africa: library profiles and ETD system. Conference proceeding of the $44^{\text {th }}$ Annual National Conference and AGM of Nigerian Library Association held at Abuja, Nigeria, pp. 18-23.

[15] Obiweluozor, N. (2015), "Early Childhood Education in Nigeria, Policy Implementation: Critique and a Way Forward", African Journal of Teacher Education, Vol 4, No 1 (2015), University of Benin, Nigeria. 
[16] Federal Republic of Nigeria (2012). National Policy on Education $\left(4^{\text {th }}\right.$ Ed.) Lagos: NERCDC.

[17] Nwaubani O. O (2004), "Effective Teaching Methods for PrePrimary school pupils in the Arts and Related Subjects", Journal of Primary Education Studies, Vol 1 No 1; ISSN: 0189-4617 A. A Akinrotimi and P. K. Olowe (2016)," Challenges in Implementation of Early Childhood Education in Nigeria: The Way Forward" Journal of Education and
Practice ISSN 2222-1735 (Paper) ISSN 2222-288 X (Online) Vol.7, No.7, 2016, www.iiste.org.

[18] Chukwbikem, P. E. I (2013). Resources for early childhood education. Mediterranean Journal of SocialSciences, 4 (8), 161-172. doi:10.5901/mjss.20. 